\title{
Quality Assurance Factors Influencing Implementation of Early Childhood Development and Education Curriculum
}

\author{
Zadock Obuchere Murundu* \\ Tom Mboya University College P.O. Box 199 Homa Bay, Kenya \\ *Corresponding Author \\ Zadock Obuchere Murundu \\ Article History \\ Received: 19.08.2019 \\ Accepted: 27.08 .2019 \\ Published: 30.08 .2019
}

\begin{abstract}
Quality of education is determined by conditions of learning in institutions. There are real concerns raised by stakeholders regarding quality of education in Early Childhood Development and Education (ECDE) centers in Emuhaya Sub-County, Kenya. Factors contributing to poor quality assurance control in implementation of ECDE curriculum are yet to be established. The purpose of the study was to establish quality assurance factors influencing implementation of ECDE Curriculum in Emuhaya SubCounty, Kenya. The study was based on descriptive survey design. It consisted of 196 teachers drawn from 98 ECDE Centres and 1Program Officer. Simple random sampling technique was used to select 65 teachers. Saturated sampling technique was used to select 1 program Officer. Data was collected by questionnaire, interview schedule and observation schedule. The study concluded that: ECDE Centres did not have adequate teaching - learning resources and facilities suitable for ECDE children. This inhibits implementation of ECDE Curriculum. The study recommends that; Intensive monitoring and evaluation system should be developed and implemented to enhance quality assurance by employing more ECDE Quality Assurance and Standards Officers to work hand in hand with The Program Officer in the process of manning ECDE subsector.
\end{abstract}

Keywords: Quality Assurance, Influence, Implementation, ECDE Curriculum.

\section{INTRODUCTION}

Quality assurance is the constant coordination, monitoring and follow - up of the process of Curriculum development and implementation. This constant monitoring identifies weak areas of Curriculum that need replacement or correction [1]. Although Republic of Kenya [2] states that, in Kenya the Quality Assurance and Standards Department shall; ensure establishment and maintenance of high educational standards in Early Childhood Development and Education (ECDE) institutions and in its service providers, The Master Plan on Education and Training 1992-2010 [3] reports that ECDE system is characterized by a weak professional management infrastructure as a large portion of quality assurance and standards officers (inspectors) and field officers have not received adequate training which is relevant to the development of children aged $0-6$ years. This is coupled with poor and inadequate facilities and resources to enable them to monitor implementation of curriculum leading to poor quality of Early Childhood Development and Education, hence the need to establish quality assurance factors influencing implementation of ECDE curriculum in Emuhaya Sub-County, Kenya.

\section{Objectives of the Study}

The study therefore aimed at exploring quality assurance factors influencing implementation of ECDE curriculum.

\section{Materials and Methodology \\ Research Design}

Descriptive survey design was used in conducting this research as Ader, Van, Deltaan \& Beekman [4] describe descriptive survey as collecting data in order to test hypothesis or to answer questions concerning the current status of the subject of study. Descriptive survey design was chosen because it is appropriate for educational fact-finding as it yields a great deal of information, which is accurate. It also enables a researcher to gather data at a particular point in time and use it to describe the nature of the

Copyright @ 2019: This is an open-access article distributed under the terms of the Creative Commons Attribution license which permits unrestricted use, distribution, and reproduction in any medium for non commercial use (NonCommercial, or CC-BY-NC) provided the original author and source are credited. 
existing conditions [5]. The research aimed at gathering accurate information and characteristics that are observable in quality assurance factors influencing implementation of ECDE Curriculum.

\section{Methodology}

Saturated sampling technique was used to sample out 1 District Program Officer. Saturated sampling technique is a non probability-sampling technique in which all members of the target population are selected because they are too few to make a sample out of them [6]. Simple random sampling technique was used to select a sample size of 65 teachers (33\% of the study population) as a third of the study population is the convenient sample size for a survey study [7]. Simple random sampling was used because it is a technique in which every member has an equal chance of being selected [8].

Teachers' Questionnaires (TQ) were used to collect data. They had; open - ended and closed ended items so as to enable the researcher to gather data from a large number of respondents at a particular time [9]. Open - ended questions gathered in - depth information while closed - ended questions gave structured responses, which facilitated the ease of tabulation and analysis [4]. Program Officer's Interview Schedule (POIS) was also used to gather data regarding quality assurance factors because all ECDE teachers in the district are directly answerable to him and report to him even without passing through the primary schools' head teachers. The researcher preferred to use an interview schedule because it provides a free environment for the respondents to express themselves and even give additional information, which has not been catered for in the questionnaire [10]. Lesson Observation Schedule (LOS) was used to gather data regarding quality assurance factors because it is practical and it exposes him to the real object or activity being investigated and allows him to participate in the exercise through; touching, seeing, feeling and testing [7].

\section{Reliability of Instruments}

To establish reliability of research instruments, a pilot study was carried out. It involved 7 teachers who were $4 \%$ of the study population [11]. The two tests were administered at an interval of two weeks. This was done so as to find out whether the terms used resonate with teachers. The researcher then verified their content for accuracy, consistency, and ensured that ambiguous information was removed while deficiencies and weaknesses were noted and corrected in the final instruments. Teachers who participated in the pilot study were not involved in the final study. This method of establishing reliability of instruments was appropriate for the instruments that gather data which is qualitative in nature [10].

\section{Validity of the Instruments}

For validity of the instruments to be ensured three experts from the Department of Educational Communication, Technology and Curriculum Studies, of Maseno University examined the content of the instruments and advised the researcher on the face validity. Improvements were made according to the suggestions made by the experts before the instruments were finally taken into the field.

\section{Data Collection Procedures}

The researcher secured a research permit and a research authorization letter attached as Appendix $E$ and $F$ respectively from the National Council for Science and Technology in the Ministry of Higher Education, Science and Technology through the School of Graduate Studies (S.G.S) of Maseno University before proceeding to the field for data collection. The researcher then reported to Emuhaya Sub-County Education Officer and Emuhaya Sub-County Program Officer's office and presented a copy of the letter of research authorization. Permission was then sought from the administrators of the sampled ECDE Centres through written letters two weeks before the study was undertaken.

For effective administration of the Teachers' Questionnaires (TQs), the researcher made a personal visit to the sampled ECDE Centres and gave teachers relevant instructions on how to fill questionnaires; he administered the questionnaires then requested teachers to fill them carefully. Where necessary, clarification was made on the items of the questionnaires. Finally, the researcher withdrew the completed questionnaires from teachers before he left for another centre to avoid loss of some questionnaires.

The researcher then personally visited the Program Officer and agreed with him on the convenient day and time when they could meet for an interview. He informed the Program Officer what he expected to research on, in advance. When the material day for the interview reached, the researcher conducted the interview with the Program Officer by reading all the questions found on the Program Officer's interview schedule (POIS) systematically; individually while the Program officer answered appropriately. At the same time, the researcher was recording the responses in a reported speech form. All respondents were assured of confidentiality and anonymity when reporting.

The researcher personally visited 6 ECDE Centres (5\% of the study sample) which were randomly selected [12] and observed at least one lesson in each ECDE Centre as teachers taught with the help of Lesson Observation Schedule (LOS). He scored marks as he made judgment accordingly and made correct conclusions and remarks. This also formed part of data collected which was used for analysis. 


\section{Methods OF DATA ANALYSIS}

Data was analyzed by use of descriptive statistics. This included the use of frequency counts, percentages and means. Data gathered by open ended questions from questionnaires, Interviews and observation was organized, categorized and reported in emergent themes as defined by Watson [13], qualitative data analysis is systematic procedure followed in order to identify essential features, themes and categories. Data recorded in verbatim form from the interview with the Program Officer was also organized, categorized and reported according to emergent themes. The researcher finally reviewed the data again to locate additional evidence backing up each theme and compared the general themes across all data sources creating broader more consistent themes.

\section{Results and Discussions \\ Quality Assurance Factors}

The study sought to find out data about; Professional qualification (for both the Program Officer and teachers), Resources and facilities (for both the Program Officer and teachers), Work/teaching load (for both the Program Officer and teachers), Teachers' preparation, Lesson presentation; Teaching and learning methods. Data was gathered through the researcher having an in depth interview with the Program Officer.

\section{Professional Qualification}

The study sought to find out the highest professional qualification of the Program Officer and its influence on the quality of ECDE Curriculum implemented. The study findings revealed that, his highest professional qualification was Diploma certificate in ECDE. This implies that he was capable of inspecting or monitoring the quality ECDE Curriculum implemented as Services Standard Guidelines for Kenya [3] states that, a program officer should be at least a holder of diploma certificate in education. When the study sought further to find out whether the Program Officer had received ECDE training relevant to the development of children in the 0 - 6 years' age group, he reported;

"I first trained as a primary school P1 teacher, then I was upgraded up to ATS - 1 (Approved teacher Status - 1) gradually, then I became a Zonal inspector of schools. From this position, I rose to the current position after undergoing a Diploma course in ECDE."

This confirms that he has undergone a special training relevant to the development of small children therefore he is capable of monitoring and inspecting implementation of ECDE Curriculum. This does not concur with Republic of Kenya [3] which states that, ECDE system is characterized by weak professional management infrastructure. MOE and HRD inspectors and field officers are expected to maintain standards in ECDE Centres but a large portion of these officers have not received training relevant to the development of children in the 0 - 6 years' age group.

When the study sought to find out professional qualification of ECDE teachers in the district and its influence on the quality of ECDE Curriculum implemented. The study findings revealed that; majority of teachers $(87.7 \%)$ in the district were trained. This implies that they had undergone a course on implementation of ECDE Curriculum hence promoting the quality of ECDE Curriculum implemented. This is contrary to Republic of Kenya and UNICEF [2] report which say that, ECDE subsector is characterized by a huge percentage of professionally unqualified teachers which has led to poor performance of the subsector.

Professional qualification of teachers in ECDE is a crucial determinant of the teachers' competence in the utilization of the teaching and learning environment which influences implementation of ECDE Curriculum [14]. Training helps the teacher to understand learning environment that is suitable for effective implementation of ECDE Curriculum. She understands how to interpret the objectives and use the right experiences suitable for the ECDE learning environment. Training makes it possible for teachers to evaluate their learning environment, their learners and themselves [15].

\section{Resources and Facilities}

The study sought to find out the adequacy of inspection resources and facilities which could enable the Program Officer to carry out inspection of the quality of the ECDE Curriculum implemented in ECDE Centres. The study findings revealed that inspection resources and facilities were inadequate. This was confirmed when he answered angrily; two chairs!"

"This office is as blank as you see it. It has nothing in terms of resources and facilities a part from these papers, a table and

When the study sought further to find out the type of resources and facilities which the Program Officer lacked to enable him to monitor the quality of ECDE Curriculum implemented smoothly, and the effect on the quality of ECDE Curriculum implemented. He said;

"ECDE as a department has really been forgotten by the Ministry of Education on the side of resources and facilities because it does not have: a vehicle for carrying out inspection; an office specifically meant for ECDE alone because the one which 
you are seeing me occupying is being shared by the other District Quality Assurance officers in charge of other Education departments in the District; and funds to run the ECDE department."

This clearly indicates that, there is lack of ECDE inspection resources and facilities. This lowers the quality of ECDE Curriculum implemented. This concurs with Republic of Kenya [3] which observes that ECDE field officers lack essential facilities and resources to enable them have a constant; coordination, monitoring and having a follow up of the ECDE Curriculum development and implementation activities in Kenya.

When the study sought to find out the quality of teaching and learning resources and facilities in ECDE Centres and its influence on ECDE Curriculum implemented. The study findings revealed that; all the ECDE Centres (100\%) in the district did not have all the required teaching and learning resources and facilities suitable for ECDE children in their learning environments. The study further revealed that; the few resources and facilities which were available in ECDE Centres were in a pathetic condition and were not fully utilized by most of the ECDE teachers. This inhibits the quality of ECDE Curriculum implemented in the district. This concurs with Koech Education Report [2] which stipulates that; many ECDE Centres in Kenya are characterized by inadequacies in basic facilities such as; properly ventilated classroom, furniture suitable for children, kitchen, safe clean water, play grounds and toilets; few have adequate qualities of instructional and play materials [2].

Republic of Kenya [16] recommends that play and learning equipment for ECDE centre shall be age and developmentally appropriate (child size, brightly coloured, adequate, safe and securely fixed to protect children from injury). The physical environment which includes the classroom setting as well as the outdoor setting, should provide opportunities for the ECDE children to explore and learn. International Association for the Education of Young Children [17] states that the quality of the physical space and material provided affects the level of involvement of the ECDE children and the quality of interaction between the teacher and the children. Nebraska Department of Education and Lowa Department of Education [18] describes an appropriate learning environment for the ECDE children as the one that provides time opportunities for children to experience and respond actively to their world. It should be social in nature providing secure and stimulating climate for all children. Lombardi [19] notes that ECDE learning environment should be based on development appropriate practice. This means that an ECDE classroom should respond to the natural curiosity of young children, reaffirm a sense of self and promote positive dispositions towards learning.

\section{Work/Teaching Load}

When the study sought to find out the Program Officer's general comment(s) on the effect of his workload on the quality of ECDE Curriculum implemented, he said;

"Am overworked since I'm the only Quality Assurance and Standards Officer (QUASO) who is in charge of all the 174 both public and private ECDE Centres in the district to add on other petty responsibilities."

This makes him fail to monitor the quality of ECDE Curriculum implemented in the district effectively as the amount of work load per an individual worker determines his/her working efficiency [20].

When the study sought to find out how often the Program Officer inspects a single ECDE centre in a year and its influence on ECDE Curriculum implemented. The Program Officer reported;

"Sometimes I may have a single inspection or visit to a few ECDE Centres in a year. Sometimes I only inspect some ECDE Centres when they have teachers who are undergoing ECDE teacher training courses that require them to be assessed by the Program Officer. Others are inspected once per term since they are nearly situated to the District Education Offices."

This confirms that there is inadequate inspection in ECDE which lowers the quality of ECDE Curriculum implemented. This concurs with Republic of Kenya [3] which observes that lack of coordination and supervision of education and training has been cited as important impediments to the provision of quality education in Kenya as quality assurance and standards officers are overworked since they are few against very many institutions.

When the study sought to find out the teacher's work/teaching load per teacher in terms of lessons taught per week and the teacher; child ratio in class; and its influence on the quality of ECDE Curriculum implemented. The study findings revealed that all teachers $(100 \%)$ in the district teach more than the required lessons per teacher in a week as a teacher is required to teach a minimum of 10 lessons and a minimum of 15 lessons per week [16]. All ECDE Centres in Emuhaya Sub-County had inappropriate teacher: child ratio than the recommended by the MOE (too many children per teacher in a class). This lowers the quality of ECDE Curriculum implemented.

This concurs with Lewin [21] who he notes that; quality of education declines as workload and the pupil: teacher ratio rises. Republic of Kenya [3] observes that because most ECDE Centres in Kenya lack financial capacity to employ sufficient number of teachers, they are unable to establish and maintain a reasonable pupil: teacher ratio hence poor quality of Curriculum implemented. 
Early childhood teachers need adequate time to focus on and interact personally with children and their families. The teacher: child ratio and group size are important in the implementation of ECDE curriculum [17]. The younger the child the more important it is to have adequate numbers of staff in the classroom. Appropriate staffing patterns vary according to the age of children, the type of the program activity, the inclusion of the children with special needs, the time of the day and other factors. Appropriate teacher: child ratios encourage the bonding of children and teachers. Republic of Kenya [16]; National Association of Elementary School Principals [22] recommend the following student teacher ratio of the ECDE children 10:1 for three to five years old; 15:1 for the six to eight years old; and not more than 15:1 for at risk children.

\section{Teachers' Preparation}

When the study sought to find out the teachers' preparation for lessons. The study findings revealed that; all teachers $(100 \%)$ in the district prepare and use schemes of work. They all mark children's class registers. Few of them, $(40 \%)$ prepare and use lesson plans on daily basis. Few teachers (30\%) keep and update their record of work covered and children's progress records. This lowers the quality of ECDE Curriculum implemented as; Curriculum planning and development is a collective responsibility of many participants [23]. Teachers should play a crucial role in the preparation for ECDE Curriculum implemented [14].

Teachers are the final planners of the Curriculum at the classroom (micro level). Teachers rely for their planning on the context and methods outlined in text books, ECDE syllabus and ECDE teachers' guidelines [24]. They make various judgements about appropriate activities, materials to be used, satisfactory levels of children achievements, necessary follow - up activities among others. They also make on - spot judgements about how children are reactive about topics that need to be recapitulated or re - taught and activities that can be omitted [25]. Teachers need to generate their own knowledge about; what to teach? When to teach? And what to use? [26]. Teachers are expected to reflect on their basic concerns about classroom interactions in their planning of curricula [27].

\section{Lesson Presentation}

When the study sought to find out the Program Officer's comment on teachers' lesson presentation. The study findings revealed that; Majority (75\%) of teachers in the district had at least an average score on lesson presentation, while a few (25\%) of teachers had a below average score on lesson presentation. This promotes the quality of ECDE curriculum implemented as; lesson presentation deals with how well an ECDE teacher is prepared to teach and how well he/she delivers the material [28].

Ambuko [29] supports this when he points out that; a well planned lesson with adequate and appropriate teaching and learning resources enable the teacher to be confident. This leads to a better lesson presentation. The evaluator of an ECDE lesson will judge the lesson presentation based on the following factors: lesson plan personalization, materials selection and utilization, voice variation, technical accuracy of information, coverage of major discussion points (content), mastery of content, questioning skills, concluding technique [22].

\section{Teaching and Learning Methods}

When the study sought to find out the Program Officers' comment on the quality of teaching and learning methods commonly used by teachers in ECDE Centres and the influence on the quality of ECDE Curriculum implemented. The study findings revealed that; majority, $(65 \%)$ of the teachers in the district use thematic method of teaching which is the best teaching method for ECDE children as it is a child centered method. This promotes the quality of ECDE Curriculum implemented. Few of them (35\%) of teachers in the district use other methods e.g. Montessori learning approach and others which are not child Centred hence not recommended for teaching ECDE children.

This concurs with Republic of Kenya [30] which recommends thematic learning approach as the only proven effective method which can be used by ECDE teachers in the facilitation of learning in ECD. Therefore, teaching and learning process should be generally participatory or child centered in nature. Shaji [31] supports when he denotes that, important techniques at the ECDE level are observation, isolation and control of variables. ECDE guidelines authored by KIE propose the use of thematic approach to teaching, which requires a child to learn various activities, integrated together in a given theme and discourages the use of Montessori approach which use individualized activity based experience approach [32].

\section{CONCLUSION}

Based on the findings, the following were the Conclusions of the study; The Program Officer was a holder of diploma certificate in ECDE. This promotes implementation of ECDE Curriculum. Majority of teachers were trained. This implied that they had undergone a course on implementation of ECDE Curriculum hence promoting implementation of ECDE Curriculum.

The Program Officer had inadequate resources and facilities to enable him to monitor implementation of ECDE Curriculum effectively these were: a vehicle, an office specifically meant for carrying out inspection and funds to run the ECDE department. ECDE Centres did not have all the required teaching, learning resources and facilities suitable for ECDE children. The few resources and facilities which were available were in a pathetic condition and were not fully utilized by ECDE teachers. This inhibits implementation of ECDE Curriculum. 
Only one Quality Assurance and Standards Officer (the District Program Officer) was in charge of all the 174 (both public and the private ECDE Centres in the district). This was a heavy work load that made him fail to monitor implementation of ECDE Curriculum effectively. Teachers taught more than the required lessons per teacher in a week. ECDE Centres had inappropriate teacher: child ratio than the recommended (too many children per teacher in a class).

All teachers prepared for lessons and used schemes of work; they marked pupils' class register. Few of them prepared and used lesson plans on daily basis. Few teachers kept and updated records of work covered and children's progress records. Majority of teachers had an average score on lesson presentation.

Majority of teachers used thematic teaching method which is a child Centred method of teaching which enhanced implementation of ECDE curriculum.

\section{RECOMMENDATIONS}

Based on the above conclusions, the study recommends that; Intensive monitoring and evaluation system should be developed and implemented to enhance quality assurance by employing more ECDE Quality Assurance and Standards Officers to work hand in hand with The Program Officer in the process of manning ECDE subsector.

Quality Assurance Officers in charge of ECDE should be provided with adequate inspection facilities and teaching resources like; buildings for offices, vehicles, stationary and funds to enable them to monitor implementation of ECDE Curriculum effectively.

ECDE teachers should prepare and use lesson plans for teaching on daily basis.

\section{References}

1. Shiundu, J.S. \& Omulando, S.J. (1992). Curriculum: Theory and Practice in Kenya. Nairobi: Oxford University Press.

2. Republic of Kenya \& UNICEF. (1994). Comprehensive Education Sector Analysis Draft Report. Nairobi: Moe \& Hrd/Unicef Kenya.

3. Republic of Kenya. (1988). Report of The Presidential Working Party on Education and Man Power for The Next Decade and Beyond (Kamunge report). Nairobi: Government Press.

4. Ader, H. J. Van Marwik, H. W. Deltaan, M \& Beekman, A. (2008). Advising on Research Methods: A Consultant's Comparison. Huizen, the Netherlands: Johannes Van Kessel Publishers.

5. Cohen, L. Manion, H. \& Morizon, K. (2000). Research Methods in Education (5th) Edition, London: Routledge Falmer.

6. Borg, R.W. \& Gall, J.P. (2007). Educational Research: An Introduction. New York: Longman Publishers.

7. Mugenda, O.M., \& Mugenda, A.G. (2003). Research Methods: Quantitative and Qualitative Approaches. Nairobi: African Centre for Technology Studies Press.

8. Bartlett, J.E., Kotrlik, J. W. \& Higgs, C.C. (2001). Organizational Research: Determining Appropriate Sample Size for Survey Research. Information Technology, Learning and Performance Journal, 19(1):43-50.

9. Ngumbo, H. (2006). Guidelines on Special Study Paper (SSP). Nairobi: Kenya Institute of Special Education.

10. Creswell, J.W. \& Miller, D.L. (2000). Determining Validity in Qualitative Inquiry. Theory into Practice, 39(3),124-131

11. Chambers, R. L., \& Skinner, C. J. (Eds.). (2003). Analysis of survey data. John Wiley \& Sons.

12. Joppe, M. (2000). The Research Process. Retrieved on $2^{\text {nd }}$ Sept. 2009. Available (Online) @http://www.ryerson.ca/ mjoppe/rp.htm

13. Watson, G. (1994). Writing a Thesis: A guide to Long Essays and Dissertations. London: Longman.

14. Mukuna, E.T. (2008). Role of Parents in Early Childhood Curriculum Development in Mumias Town; Unpublished. M. Ed Thesis. Maseno University.

15. Ong'ang'a, H.M. (2004). Factors Influencing Pre - School Teachers: Use of Thematic Approach in Teaching Pre- School Children in Kasarani Division, Nairobi Province, Kenya. A Dissertation Submitted in the Department of Early Childhood Education: Unpublished Kenyatta University MEd Thesis.

16. (2006). National Early Childhood Policy Framework. Nairobi: Government Press.

17. International Association for the Education of Young Children. (1991). Accreditation Criteria and Procedures of the National Academy of Early Childhood Program (Rev. Ed) Washington, DC: Author.

18. Kelly, M. (2001). The Primary Program: Growing and Learning in the Heartland.

19. Lombardi, J. (1992). Beyond Transition: Ensuring Continuity in Early Childhood Services. ERIC Digest.

20. ILO. (2001). Training for Work in the Information Sector, Evidence from Kenya. Turin: ILO.

21. Lewin, K.M. (1987). Education in Austerity: Opinions for Planners. Paris: UNESCO

22. National Association of Elementary School Principals. (1990). Early Childhood Education and the Elementary School Principals: Standards for Quality Programs for Young Children. Washington DC: Author. Cited on 12 th June 2009@htt://www.naesp.ecde.org

23. Farrant, J.S. (1986). Principles and Practice of Education. Singapore: Longman publishers Limited.

24. Marsh, C. J. \& Willis, G. (1999). Curriculum: Alternative Approaches, Ongoing Issues: $2^{\text {nd }}$ Edition. New Jersey: Prentice Itall.

25. Olson, J. (1989). Surviving Innovation; Reflecting on the Pitfalls of Practice. Journal for Curriculum Studies, 21(6): 503-508. 
26. Bahor, L. \& Georges, P.S. (1994). Teachers as Change Agents: Implications for How Teachers Use Curriculum Knowledge. Paper Presented at the Annual Meeting of the American Educational Research Association, New Orleans.

27. Giroux, H.A. (1991). Curriculum Planning Schooling and Democratic Struggle: NASSP Bulletin, 75,(532):12 - 25.

28. Epstein, S. (1995). School/Family/Community Partnerships Carting For The Children We Share. Baltimore University, 76(9)705 707.

29. Ambuko, B.S. (2008). Selection and Use of Media in Teaching Kiswahili in Secondary Schools in Emuhaya District, Kenya. Unpublished M. Ed Thesis, Maseno University.

30. (2008). Handbook for Early Childhood Development and Education. Syllabus. Nairobi: KIE.

31. Shaji, G.M. (2007). Attitude of Pre - School Teachers towards Science Curriculum in Kakamega Municipality, Kenya. Unpublished M. Ed Thesis, Maseno University.

32. (1999). Report of The Commission of Enquiry in to The Education System of Kenya (Koech report). Nairobi: Government Press. 